\section{EMBRYRIDDLE}

Aeronautical University

SCHOLARLY COMMONS
Journal of Aviation/Aerospace

Education \& Research

Volume 6

Number 1 JAAER Fall 1995

Article 7

Fall 1995

\title{
The Bootstrap Approach to Predicting Airplane Flight \\ Performance
}

John T. Lowry

Follow this and additional works at: https://commons.erau.edu/jaaer

\section{Scholarly Commons Citation}

Lowry, J. T. (1995). The Bootstrap Approach to Predicting Airplane Flight Performance. Journal of Aviation/Aerospace Education \& Research, 6(1). https://doi.org/10.15394/jaaer.1995.1167

This Article is brought to you for free and open access by the Journals at Scholarly Commons. It has been accepted for inclusion in Journal of Aviation/Aerospace Education \& Research by an authorized administrator of Scholarly Commons. For more information, please contact commons@erau.edu. 


\title{
THE BOOTSTRAP APPROACH TO PREDICTING AIRPLANE FLIGHT PERFORMANCE
}

\author{
John T. Lowry
}

The Bootstrap Approach (TBA) to flight performance is, for fixed-pitch propeller-driven airplanes, a set of simple formulas in nine aircraft parameters-four from brief flight tests-plus the variables of aircraft weight and air density. The formulas are derivable from the empirically supported linearity of the propeller polar. TBA outputs include five full-throttle or gliding $V$-speeds $\left(V_{x} V_{y} V_{m} V_{b g} V_{m d}\right)$ and a common version of longrange cruise speed $\left(V_{L R C}\right)$ as well as, for any air speed, thrust, drag, rate of climb (thereby service ceiling) or descent, and flight path angle. Knowledge of engine speed (RPM) and fuel consumption rate allows calculation of (partial-throttle) speeds $V_{b r}$ for best range and $V_{b e}$ for best endurance. An extension of TBA to airplanes with constant-speed propellers substitutes two different propeller parameters and suggests a general propeller chart. Though based on empirical graphs rather than formulas, this extension easily incorporates partial-throttle operation.

\section{INTRODUCTION}

The first seven sections numbered below constitute a guided tour of TBA using realistic numbers for a Cessna 172. Theory we skip over in favor of practical demonstration that can be found elsewhere (Lowry, 1996) as can some operational details, such as calibrating the air speed indicator and adjusting for non-standard atmospheres (Lowry, 1995).

After the tour we discuss extensions of TBA to nonfull-throttle powered V-speeds and to constant-speed propeller-driven aircraft.

\section{Required and Optional Tools}

One must have an airplane (we take for our example a 1986 Cessna $172 \mathrm{P}$ in zero-flaps configuration) with a known empty weight, a method of assessing fuel usage, a well-calibrated air speed indicator, and a few other instruments (altimeter, tachometer, compass, heading indicator, and outside air thermometer). The pilot must be capable of holding air speed during steady climbs, glides, and level flight, within a knot or so. It is best to have an observer riding along to record data and, for that job, a clipboard, data sheets, and pencils. A stopwatch and hand calculator also are required in the cockpit. Once the nine numbers making up the Bootstrap Data Plate (BDP) have been accumulated or calculated, it saves much labor to use a desktop computer and spreadsheet program to crank out the voluminous performance data output.

\section{The Easy Bootstrap Data Plate Items}

Of the nine items needed, five come from the Pilots Operating Handbook (POH) or common knowledge. These five, with values for our sample Cessna 172P, are:

1) Reference wing area $S=174 \mathrm{ft}^{2}$.

2) Wing aspect ratio $A\left(=B^{2} / S, B=\right.$ wing span $=$ $35.83 \mathrm{ft})=7.378$.

3) Mean sea level (MSL) full-throttle rated torque $M_{0}=P_{0} / 2 \pi n_{0}\left(P_{0}\right.$ rated power, $n_{0}$ rated propeller revolutions per second). For this $172, \mathrm{P}_{0}=160 \mathrm{HP}=$ $88,000 \mathrm{ft}-1 \mathrm{bs} / \mathrm{sec}$ and $\mathrm{n}_{0}=2700 / 60=45 \mathrm{rps}$. Hence $\mathrm{M}_{0}=$ $311.2 \mathrm{ft}-\mathrm{lbs}$. In most of our formulas, though it makes them a little longer, we'll retain $P_{0}$ and $n_{0}$.

4) The proportional mechanical power loss independent of altitude, $C$, which can almost always be taken as 0.12 . This governs full-throttle torque at altitude through the power-drop-off factor $\phi$ (Greek small phi):

$$
M(\sigma)=\phi(\sigma) \times M_{0}
$$

Relative atmospheric density (Greek small sigma) $\sigma$ $\equiv \rho / \rho_{0}$ (Greek small phi) where $\rho$ is atmospheric density and standard density $\rho_{0}=0.002377 \mathrm{slug} / \mathrm{ft}^{3}$. The timehonored form (Gagg \& Farrar, 1934) for this drop-off factor is:

$$
\phi(\sigma)=\frac{\sigma-C}{1-C}
$$

5) Propeller diameter $d=6.25 \mathrm{ft}$. 
To simplify later calculations, it's convenient to assume a "standard weight" for the airplane. For our example we choose $\mathrm{W}_{0}=2400 \mathrm{lbs}$, maximum certified gross weight. Standard relative air density is taken to be unity.

\section{Glide Tests for Two Drag Parameters}

Of the four remaining BPD items, two typify drag characteristics and two thrust characteristics. The drag numbers are the usual:

6) Parasite drag coefficient, $C_{D D}$ -

7) Airplane efficiency factor, $e$.

Getting $\mathrm{C}_{\mathrm{D} 0}$ and $e$ through linear regression analysis of many glides is overkill. One can simply find, by trial and error, the speed for best glide $V_{b g}$ and its corresponding glide angle $\gamma_{\mathrm{bg}}$ (Greek small gamma) at one known aircraft weight $W$ in an atmosphere of known relative density $\sigma$. Let us take $W=2200 \mathrm{lbs}$ and $h_{p}=$ $5000^{\prime}$. That latter makes $\sigma=0.86167$ and $\phi(\sigma)=$ 0.84281 . (We carry more decimal places than makes strict sense for convenience of the checking reader.)

Consider that we time glides from $5100^{\prime}$ to $4900^{\prime}$; $\Delta \mathrm{h}=200^{\prime}$. Glide angle is shallowest when product $\mathrm{V} x$ $\Delta t$, speed times elapsed time, is greatest. To find that maximum $\mathrm{V}$ can just as well be calibrated air speed $\mathrm{V}_{\mathrm{C}}$. Best glide angle is (later) calculated from

$$
\gamma_{b g}=\sin ^{-1}\left(\frac{\Delta h}{V_{T b g} \Delta t}\right)
$$

The relation between the two types of air speed is of course given by:

$$
V_{T}=\frac{V_{C}}{\sqrt{\sigma}}
$$

For our sample Cessna, take $\mathrm{V}_{\mathrm{Cbg}}=70.0 \mathrm{KCAS}=$ $118.15 \mathrm{ft} / \mathrm{sec}$ and $\Delta t=17.0 \mathrm{sec}$. From Equation 4, $\mathrm{V}_{\mathrm{Tbg}}=$ $75.41 \mathrm{KTAS}=127.28 \mathrm{ft} / \mathrm{sec}$. From Equation 3, $\gamma_{\mathrm{bg}}=$ $5.30^{\circ}$.

The two required drag parameters are obtained from:

$$
C_{D 0}=\frac{W \sin \gamma_{b g}}{\rho_{0} V_{C b g}{ }^{2} S}
$$

$$
\begin{aligned}
e & =\frac{4 C_{D O}}{\pi A \tan ^{2} \gamma_{b g}} \\
& =\frac{4 W \cos \gamma_{b g}}{\pi A \tan \gamma_{b g} \rho_{0} V_{C b g}^{2} S}
\end{aligned}
$$

Substituting our sample numbers into Equations 5 and 6 gives us $C_{\mathrm{D} 0}=0.0352$ and $e=0.7054$. These numbers (especially $C_{D 0}$ ) will be different if we lower some flap.

4. Climb and Level Flight Tests for Two Thrust Parameters

The driving approximation behind the fixed-pitch Bootstrap Approach is that the so-called "propeller polar diagram" is closely linear (Von Mises, 1959). This is especially true for the main range of operating speeds, excluding early take off and diving under power:

$$
\frac{C_{T}}{J^{2}}=m \frac{C_{P}}{J^{2}}+b
$$

Here $C_{T}$ is the propeller thrust coefficient, $J$ the propeller advance ratio $V / n d$, and $C_{P}$ the propeller power coefficient. Our last two BDP items are:

8) The slope of the linear propeller polar, $m$.

9) The intercept of the linear propeller polar, $b$.

Of several alternative flight test regimens for evaluating $m$ and $b$, we choose: trial-and-error climbs to find speed for best angle of climb, $V_{x}$ and $b$, followed by a test for maximum level flight speed, $V_{m}$, to find $m$.

$V_{x}$ is the full-throttle partner of $V_{b g}$, the biggest positive (smallest negative) glide angle you can achieve. Accordingly, when product $\mathrm{V} \times \Delta \mathrm{t}$ is smallest one has found $V_{x}$ For our sample Cessna 172, assume $V_{C x}=$ $60.50 \mathrm{KCAS}=102.12 \mathrm{ft} / \mathrm{sec}$. The true value is then $V_{T x}$ $=\mathrm{V}_{\mathrm{x}}=65.18 \mathrm{KTAS}=110.01 \mathrm{ft} / \mathrm{sec}$. The Bootstrap formula which finds us polar intercept $b$ is:

$$
b=\frac{S C_{D O}}{2 d^{2}}-\frac{2 W^{2}}{\rho^{2} d^{2} S \pi e A V_{x}^{4}}
$$

Substituting our sample values into Equation 8 gives $b=-0.06338$. 
Table 1

Sample Cessna 172 (Zero Flap) Bootstrap Data Plate

\begin{tabular}{||l|c|c|c||}
\hline \multicolumn{1}{|c|}{ BDP Item } & Value & Units & Aircraft Subsystem \\
\hline Wing reference area, $S$ & 174 & $\mathrm{ft}^{2}$ & Airframe \\
\hline Wing aspect ratio, $A$ & 7.378 & & Airframe \\
\hline Rated MSL torque, $\mathrm{M}_{\mathbf{0}}$ & 311.2 & $\mathrm{ft}$ - lbs & Engine \\
\hline Altitude drop-off factor, $C$ & 0.12 & & Engine \\
\hline Propeller diameter, $d$ & 6.25 & $\mathrm{ft}$ & Propeller \\
\hline Parasite drag coefficient, $\mathrm{C}_{\mathrm{D} 0}$ & 0.0352 & & Airframe \\
\hline Airplane efficiency factor, $e$ & 0.7054 & & Airframe \\
\hline Propeller polar slope, $m$ & 1.7406 & & Propeller \\
\hline Propeller polar intercept, $b$ & -0.06338 & & Propeller \\
\hline
\end{tabular}

$G$, and $H$ ) actually occur in TBA formulas for $V$ speeds or for thrust, drag, rate of climb or descent, and angle of climb or descent. In the V-speed formulas only certain combinations (called $Q, R, U$ ) of those combinations occur.

We did all the flight tests to determine the four harder-to-get BDP parameters at $5000^{\prime}$ and at $W=2200 \mathrm{lbs}$.

We conclude our flight tests with a full-speed level run (still at 5000', still at $2200 \mathrm{lbs}$ ) and find $\mathrm{V}_{\mathrm{Cm}}=105$ $\mathrm{KCAS}=177.22 \mathrm{ft} / \mathrm{sec}$. In the true terms needed in our formulas, $\mathrm{V}_{\mathrm{Tm}}=\mathrm{V}_{\mathrm{m}}=113.11 \mathrm{KTAS}=190.92 \mathrm{ft} / \mathrm{sec}$. The Bootstrap formula for polar slope $m$ is:

$$
m=\frac{2 n_{0} d W^{2}}{\phi(\sigma) P_{0} \rho S \pi e A}\left(\frac{1}{V_{m}^{2}}+\frac{V_{m}^{2}}{V_{x}^{4}}\right)
$$

Substituting our values into Equation 9 gives us $m=$ 1.7406. That completes the nine-number Bootstrap Data Plate for this (flaps-up) configuration of this particular aircraft. See Table 1.

An advantage of the Bootstrap Approach for manufacturers of small airplanes is that design changes (for example, a different engine) only require, for new performance predictions, new BDP items for the engine. The three subsystems are independent.

\section{Composite Bootstrap Parameters to Ease Calculation}

Almost everything about the airplane's full-throttle steady-state (non-accelerating) flight performance depends on the nine BDP items plus two variables, weight $W$ and relative atmospheric density $\sigma$. But only certain combinations of those nine numbers (called $\mathrm{E}, \mathrm{F}$,
The results we got did not depend on those choices; BDP parameters only depend on the particular airplane and its flap/gear configuration. Running the flight tests at some other altitude and/or some other weight we'd have gotten, within experimental error, the same BDP values.

But performance numbers (rates of climb, V-speeds, etc.) obviously do depend on gross weight and on density altitude. Again for brevity's sake, we will consider this airplane's behavior at one particular weight (maximum gross weight $\mathrm{W}_{0}=2400 \mathrm{lbs}$ ) and at two particular density altitudes (MSL and 10,000'). These choices let us compare our performance numbers with the airplane's $\mathrm{POH}$. Looking ahead to that comparison, let us evaluate, for those two cases, all the above composite Bootstrap parameters.

The composite definitions and their dependence on weight and air density are:

$$
\begin{array}{r}
E=\phi(\sigma) E_{0}, \text { with } E_{0}=\frac{m P_{0}}{n_{0} d} \\
F=\sigma F_{0}, \text { with } F_{0}=\rho_{0} d^{2} b \\
G=\sigma G_{0}, \text { with } G_{0}=\frac{1}{2} \rho_{0} S C_{D 0}
\end{array}
$$




$$
\begin{array}{r}
H=\left(\frac{W}{W_{0}}\right)^{2} \frac{1}{\sigma} H_{0}, \text { with } H_{0}=\frac{2 W_{0}^{2}}{\rho_{0} S \pi e A} \\
K=\sigma K_{0} \text {, with } K_{0}=F_{0}-G_{0} \\
Q=\frac{\phi(\sigma)}{\sigma} Q_{0} \text {, with } Q_{0}=\frac{E_{0}}{K_{0}} \\
R=\left(\frac{W}{W_{0}}\right)^{2} \frac{1}{\sigma^{2}} R_{0}, \text { with } R_{0}=\frac{H_{0}}{K_{0}} \\
U=\left(\frac{W}{W_{0}}\right)^{2} \frac{1}{\sigma^{2}} U_{0}, \text { with } U_{0}=\frac{H_{0}}{G_{0}}
\end{array}
$$

For the composite parameters' value for the two cases, see Table 2.

Now we are ready to use this collection of numbers to get useful information.

6. Full-Throttle and Gliding V-Speeds

TBA formulas for the five V-speeds as true air speeds (in $\mathrm{ft} / \mathrm{sec}$ ) are:

Table 2

Composite Bootstrap Parameters for Two Situations

\begin{tabular}{|c|c|c||}
\hline Variable or Composite & Case 1, MSL & Case 2, 10,000 Ft \\
\hline W & $2400 \mathrm{lbs}=\mathrm{W}_{0}$ & $2400 \mathrm{lbs}=\mathrm{W}_{0}$ \\
\hline & 1.00000 & 0.73848 \\
\hline $\mathrm{E}$ & 1.00000 & 0.70282 \\
\hline F & $544.614=\mathrm{E}_{0}$ & 382.764 \\
\hline $\mathrm{G}$ & $-0.00588493=\mathrm{F}_{0}$ & -0.00434589 \\
\hline H & $0.00727932=\mathrm{G}_{0}$ & 0.00537562 \\
\hline $\mathrm{K}$ & $1,703,531=\mathrm{H}_{0}$ & $1,601,954$ \\
\hline $\mathrm{Q}$ & $-0.0131643=\mathrm{K}_{0}$ & -0.00972151 \\
\hline$R$ & $-41,370.7=\mathrm{Q}_{0}$ & $-39,372.8$ \\
\hline$U$ & $-129,405,794=\mathrm{R}_{0}$ & $-237,289,514$ \\
\hline & $234,023,232=\mathrm{U}_{0}$ & $429,125,013$ \\
\hline
\end{tabular}

$$
\begin{gathered}
V_{m}=\sqrt{\frac{-E-\sqrt{E^{2}+4 K H}}{2 K}}=\sqrt{-\frac{Q}{2}+\sqrt{\frac{Q^{2}}{4}+R}} \\
V_{y}=\sqrt{\frac{-E-\sqrt{E^{2}-12 K H}}{6 K}}=\sqrt{-\frac{Q}{6}+\sqrt{\frac{Q^{2}}{36}-\frac{R}{3}}} \\
V_{x}=\left(\frac{-H}{K}\right)^{1 / 4}=(-R)^{1 / 4} \\
V_{b g}=\left(\frac{H}{G}\right)^{1 / 4}=U^{1 / 4} \\
V_{m d}=\left(\frac{H}{3 G}\right)^{1 / 4}=\left(\frac{U}{3}\right)^{1 / 4}=0.7598 V_{b g}
\end{gathered}
$$

Since the three full-throttle V-speeds depend on only two composite numbers, $Q$ and $R$, there must be a connection among them. The three are related via:

$$
V_{x}=\left(\frac{3 V_{y}^{2}-V_{m}^{2}}{V_{m}^{-2}+V_{y}^{-2}}\right)^{1 / 4}
$$

Table 3 shows the results of using the above formulas to compute V-speeds for our sample Cessna 172 in its two different situations and compares those results, when $\mathrm{POH}$ data allows, with the Cessna 172P Handbook. Though the formulas give $V$ speeds in British Engineering Units, $\mathrm{ft} / \mathrm{sec}$, we've rewritten Table 3 in terms of KTAS.

7. Additional Flight Performance Quantities

TBA is not limited to $\mathrm{V}$ speeds. In this section we present formulas, in terms of composite parameters, for full-throttle power available $P_{\text {as }}$ power required $P_{r e}$, excess power $P_{x}$, thrust $T$, drag $D$, rate of climb $R / C$, 
and flight path angle $\gamma$. In the gliding case, rate of sink $\mathrm{R} / \mathrm{S}$ and glide path angle can be obtained from the powered forms by setting $E=F=0$ and replacing $K$ by $-\mathrm{G}$.

$$
\begin{array}{r}
P_{\alpha v} \equiv T V=E V+F V^{3} \\
P_{r e} \equiv D V=G V^{3}+H / V \\
P_{x s} \equiv P_{\alpha v}-P_{r e}=E V+K V^{3}-H / V \\
T(V)=E+F V^{2} \\
D(V)=D_{p}(V)+D_{i}(V)=G V^{2}+\frac{H}{V^{2}} \\
R / C(V)=\frac{P_{x s}(V)}{W}=\frac{E V+K V^{3}-H / V}{W} \\
\gamma(V)=\sin ^{-1}\left[\frac{E+K V^{2}-H / V^{2}}{W}\right]
\end{array}
$$

Figures 1 through 4 show graphically, for the MSL case, how these quantities vary with true air speed.

EXTENSION OF TBA TO

PARTIAL-THROTTLE PERFORMANCE

We have so far neglected the important operating $\mathrm{V}$ speeds for best range $\left(V_{b r}\right)$, for best endurance $\left(V_{b e}\right)$, and any long-range cruise speed $\left(V_{L R C}\right)$. Each is characterized by only partial throttle and that presents a problem. But

Table 3

Cessna 172 TBA and POH V-Speeds (KTAS) in Two Situations

\begin{tabular}{||c|c|c|c|c||}
\hline & \multicolumn{2}{|c|}{ Case 1, 2400\# at MSL } & \multicolumn{2}{c|}{ Case 2, 2400\# at 10,000 ft. } \\
\hline V-Speed & TBA & POH & TBA & POH \\
\hline $\mathrm{V}_{\mathrm{m}}$ & 115.4 & 121.0 & 105.9 & 115.0 \\
\hline $\mathrm{V}_{\mathrm{y}}$ & 75.9 & 76.0 & 78.6 & 82.6 \\
\hline $\mathrm{V}_{\mathrm{x}}$ & 63.2 & 62.0 & 73.5 & 76.8 \\
\hline $\mathrm{V}_{\text {bg }}$ & 73.3 & 66.0 & 85.3 & 76.8 \\
\hline $\mathrm{V}_{\text {md }}$ & 55.7 & NA & 64.8 & NA \\
\hline
\end{tabular}

not an insuperable one.

The Bootstrap Approach is a "reduced" description of aircraft performance. There is only one propeller relation, the propeller polar. Since propeller forces are in two directions (axial and tangential), two relations are required for the whole story. The missing piece, in general, is propeller efficiency because we don't know, from TBA theory alone, engine RPM. Instead, we know torque. If one flies the airplane and records RPM, however, all is forgiven and propeller efficiency is forthcoming.

For example one could make a series of full-throttle climbs, at various speeds, recording engine RPM. For each such climb the pilot would know advance ratio $J=$ $V / n d$ and would know propeller efficiency $\eta=P_{a v} / P$ because $P_{a v}$ would still be given by Equation 24 and brake power $\mathrm{P}=2 \pi n \phi(\sigma) \mathrm{M}_{0}$ would, knowing $n$, also be accessible. The pilot would end with a graph or table of $\eta$ vs. $J$. Alternatively, though it's usually limited to only a narrow range of $J$ values, one might get efficiency information from the $\mathrm{POH}$ cruise table.

Where $V_{b r}, V_{b e}$, and $V_{L R C}$ are concerned we have an additional important piece of information. Each is a speed of level flight; hence thrust $T$ is equal to drag $D$. Though it involves eight relations in eight variables, the above is enough to solve the problem. Untangling those equations gets to a single one:

$$
D \times(1-m \eta J)-\rho d^{2} b V^{2}=0
$$

where $D$ is given by Equation 28. For fixed $V, W$, and $\sigma$, one runs trials on engine speed $n$. It helps to have a spreadsheet program with a "Solve For" or "Backsolver" facility.

The above procedure must be repeated for a substantial range of air speeds $V$. The specific fuel consumption rate $c$ (lbs of fuel per unit time per unit power) can be obtained from the engine manual as a function of brake power $\mathrm{P} . \mathrm{V}_{\mathrm{br}}$ is the speed which maximizes $\mathrm{V} / \mathrm{cP} ; \mathrm{V}_{b c}$ is the speed which maximizes $1 / \mathrm{cP}$. For a sample Cessna 172 at 4000' 
Figure 1

Power Available, Required, and Excess

Cessna 172, 2400\#, MSL, Flaps Up

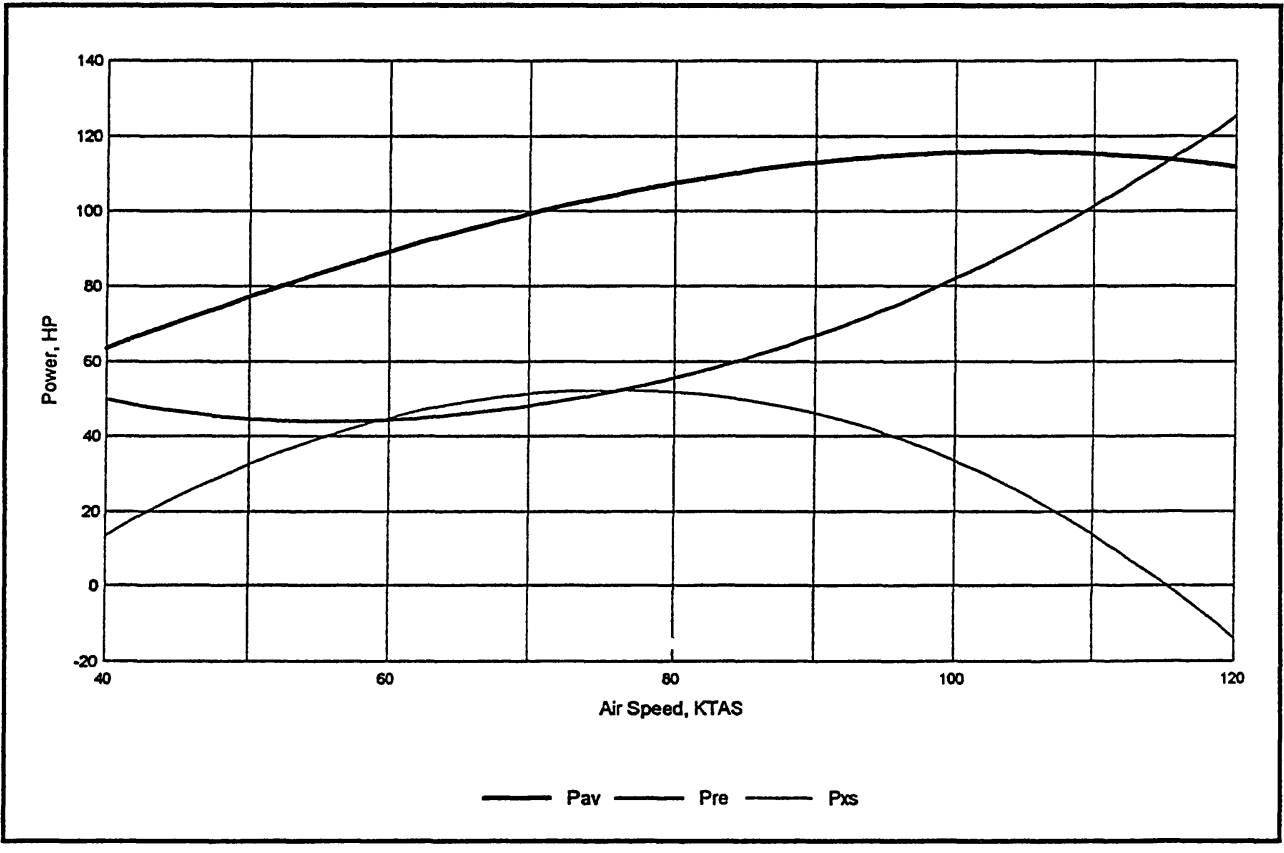

Figure 2

Thrust and Drag (Parasite, Induced, Sum)

Cessna 172, 2400\#, MSL, Flaps Up

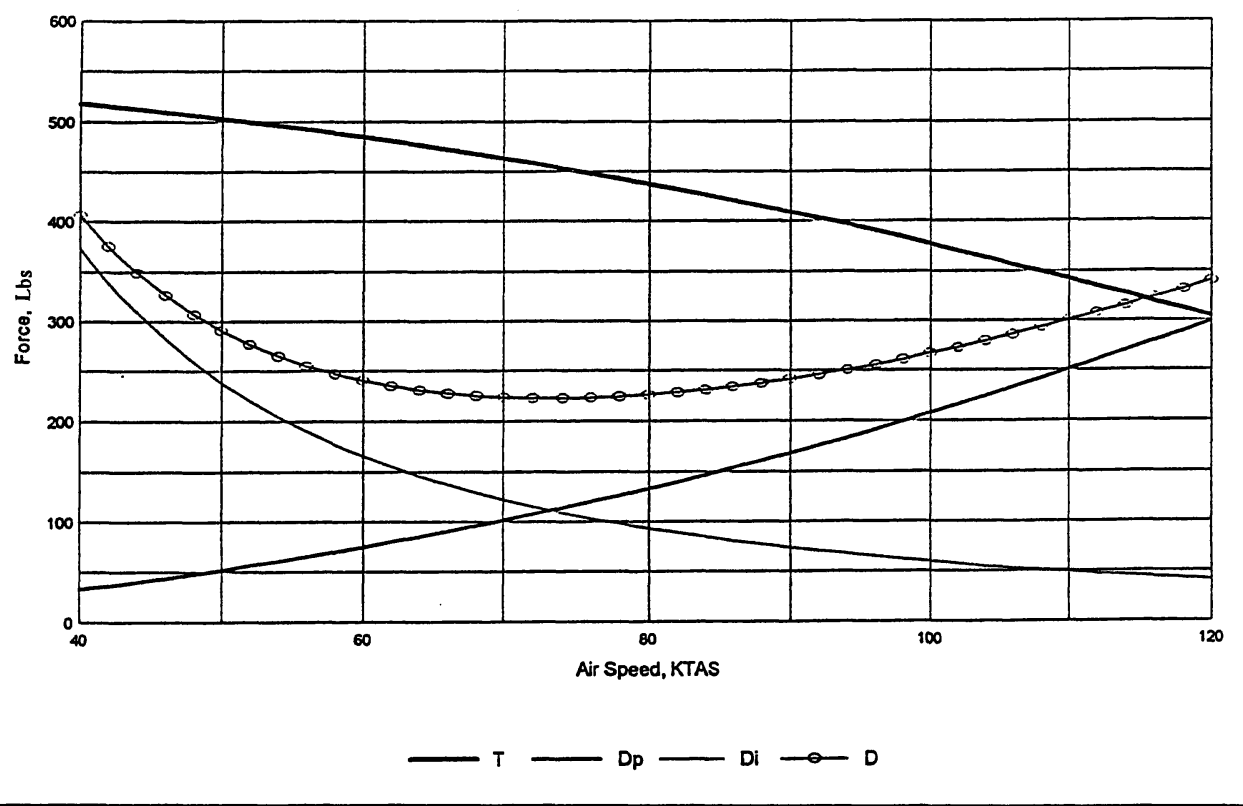


Figure 3

Rate of Climb vs. Air Speed

Cessna 172, 2400\#, MSL, Flaps Up

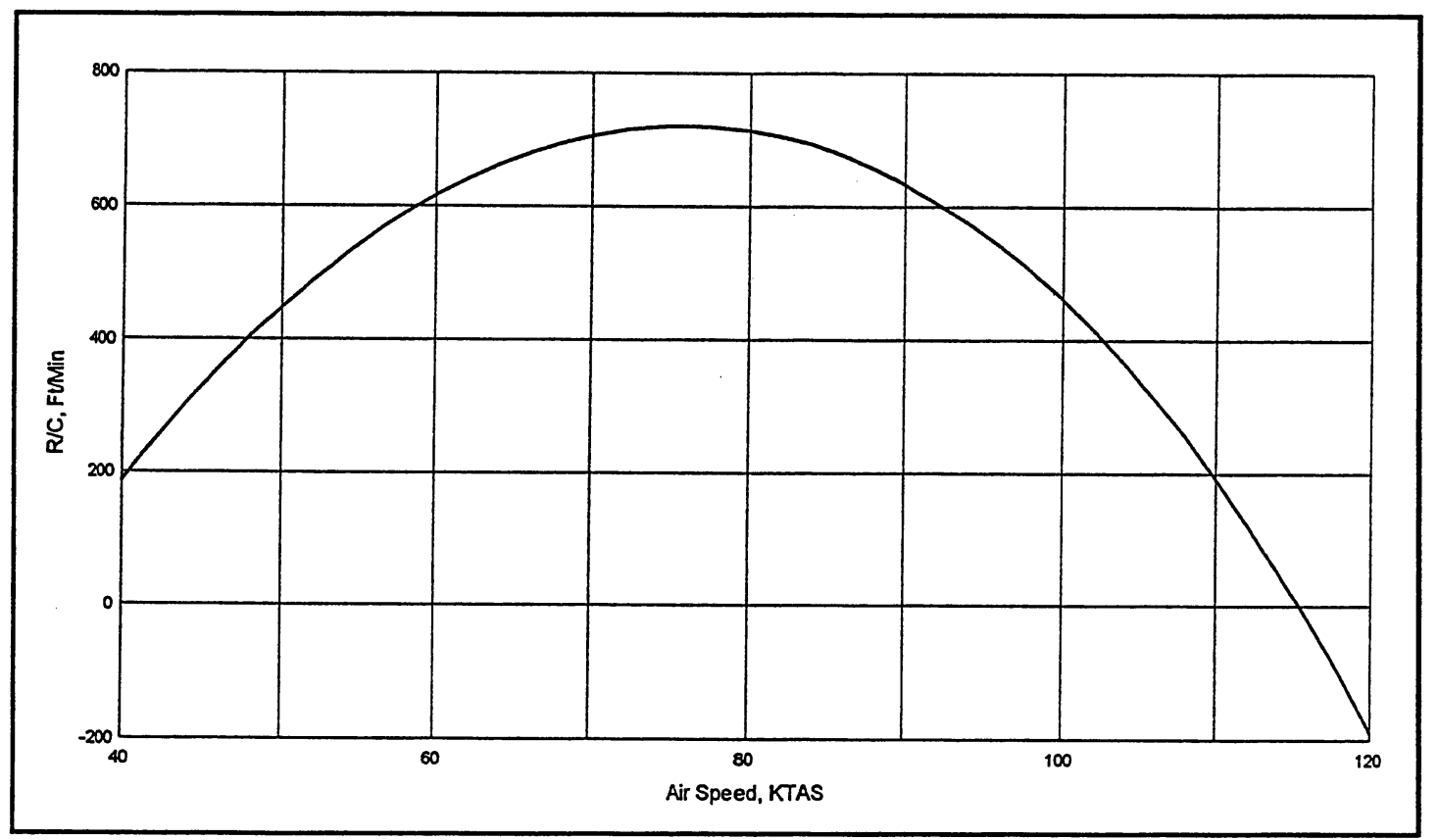

Figure 4

Flight Path Angle vs. Air Speed

Cessna 172, 2400\#, MSL, Flaps Up

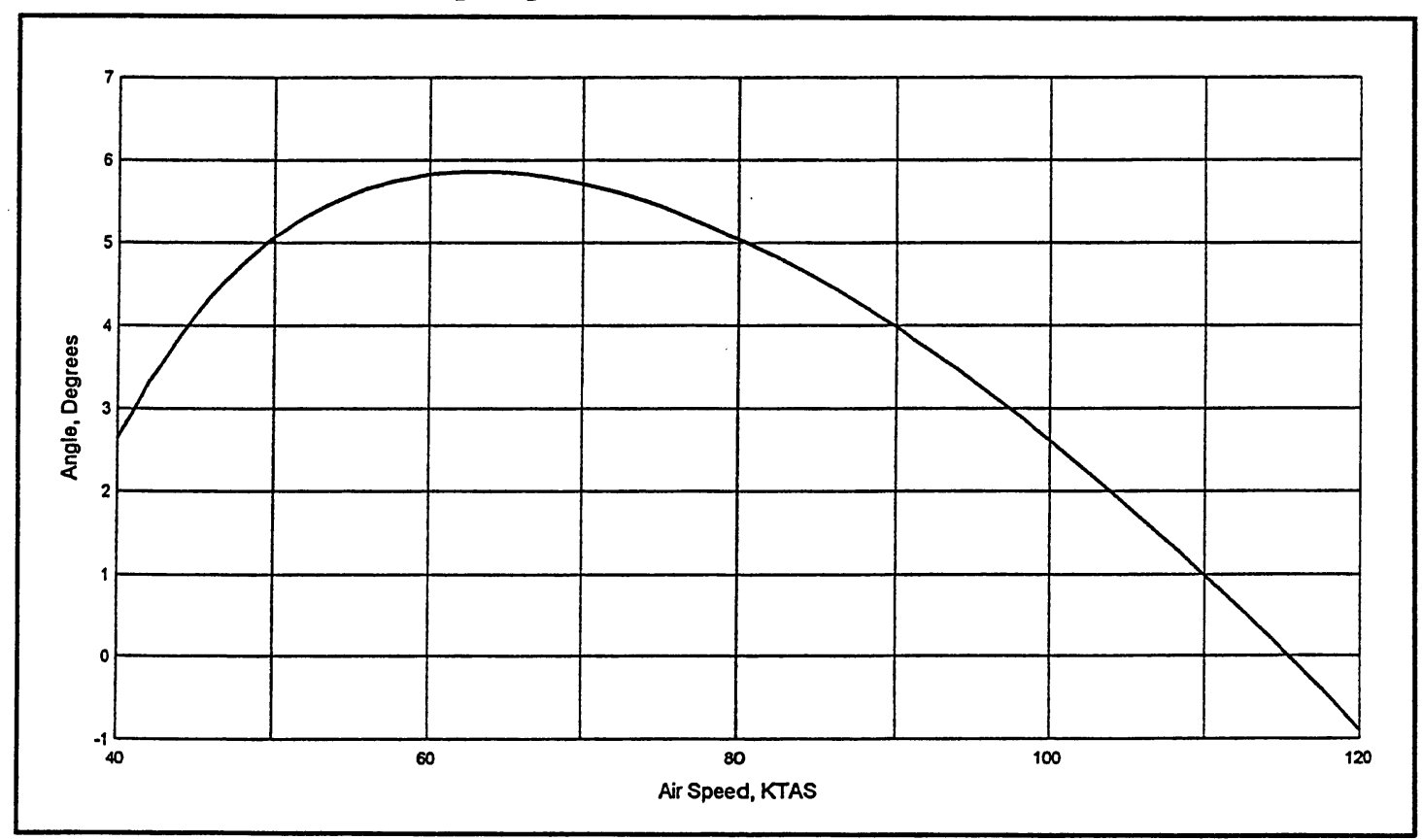


and weighing $2400 \mathrm{lbs}$, $\mathrm{V}_{\mathrm{br}}=81.0 \mathrm{KTAS}$ and $\mathrm{V}_{\mathrm{be}}=64.7 \mathrm{KTAS}$; with its 40 gallons of fuel exhausted, $W=2160 \mathrm{lbs}$, $\mathrm{V}_{\mathrm{br}}=77.0 \mathrm{KTAS}$ and $\mathrm{V}_{\mathrm{be}}=61.5$ KTAS. Running from the high to the low weight, always at the appropriate speed, total endurance was 8.56 hours and total range was $605.0 \mathrm{~nm}$. These results are off the $\mathrm{POH}$ Range and Endurance Profiles to the low speed sides and to the high range and high endurance sides. No one wants to go so slow.

That's where $V_{\text {LRO }}$ long-range cruise speed, comes in. What's missing is a universally accepted definition of long-range cruise speed. Alternative definitions might depend on many disparate economic factors. Transporting private soldiers might give one (slower) value; transporting captains of industry, another higher. Following the ideas of B. H. Carlson (Smith, 1985), one might take $V_{\text {LRC }}$ to be Carlson's "cruiseoptimum air speed," the speed for minimum ratio $D / V$. Doing so, calculation with Equation 28 gives:

$$
V_{L R C}=3^{1 / 4} V_{b g}=1.316 V_{b g}
$$

For our Cessna 172 at $4000^{\prime}$ weighing $2400 \mathrm{lbs}$, we then have $\mathrm{V}_{\mathrm{LRC}}=1.316 \times 77.8=102.4 \mathrm{KTAS}, 23$ knots faster than the corresponding $\mathrm{V}_{\mathrm{br}}$

\section{EXTENSION OF TBA TO}

\section{CONSTANT-SPEED PROPELLER AIRCRAFT}

Constant-speed propellers are a challenge to TBA because, with the reference blade angle no longer fixed, propeller polar coefficients $m$ and $b$ (especially $m$ ) are no longer constant. But again the problem is not insuperable.

In one sense a constant-speed propeller is simpler than one with fixed pitch. As long as one doesn't run up against the low- or high-pitch stop, engine RPM is constant. With fixed throttle (fixed torque), then, one has fixed power.

In the fixed-pitch polar, variable $\mathrm{C}_{\mathrm{P}} / \mathrm{J}^{2}$, at constant torque, depended only on air speed. In the constantspeed case it is variable $\mathrm{J} / \mathrm{C}_{\mathrm{P}}{ }^{\text {t/ }}$ which, now at constant power, depends only on air speed. Skipping over a fairly complex algebraic way of tying $J / C_{P}{ }^{3 /}$ to the linear propeller polar; the end result is a form of Boeing Airplane Company's (BAC) old General Propeller Chart (Perkins \& Hage, 1949). Because of the vast difference in scale between World War II multi-engine transports or bombers and current general aviation airplanes, the BAC General Propeller Chart doesn't give very accurate results in the smaller case. But there's nothing wrong with the idea, so we simply recast it (Figure 5) using data and measurements from a general-aviation sized constantspeed propeller.

To use the General Aviation General Propeller Chart requires values of $J / C_{P}{ }^{3}$ and of $C P X \equiv C_{P} / X$. The propeller power coefficient $C_{P}$ is: 


$$
C_{P}=\frac{P}{\rho n^{3} d^{5}}
$$

Power adjustment factor $\mathrm{X}$ is given by

$$
X=0.0011 T A F+6.5 \times 10^{-7} T A F^{2}
$$

where Total Activity Factor (TAF) is the product of the number of propeller blades (per propeller) and the Blade Activity Factor (BAF) of one. This last is defined as:

$$
B A F=\frac{100,000}{32} \times \int_{2}^{1} x^{3} \frac{b}{R} d x
$$

where relative propeller station $x$ is $r / R$ ( $r$ is distance from the shaft to the station, $R$ the blade radius) and $b$ is the width of the blade (in the same units as $R$ ) at $X$.

One additional wrinkle must be ironed out. Air coming into the propeller comes in a bit slower than the airplane's true air speed; the fuselage obstructs and deflects the flow. We use SlowDown Factors adapted from early British and American data (Diehl, 1936). For the tractor propeller,

$$
S D F_{T}=1.05263-0.00722 Z-0.16462 Z^{2}-0.18341 Z^{3}
$$

for the pusher propeller,

$S D F_{P}=1.05263-0.04185 Z-0.01481 Z^{2}-0.62001 Z^{3}$

$Z$ is the ratio of propeller diameter to fuselage diameter, the latter measured one propeller diameter from the plane of the propeller. The larger-than-unity leading terms compensate for the General Aviation General Propeller Chart data being for a propeller on a small nacelle, not one in free air.

In summary, the constant-speed case makes use of the two propeller parameters TAF and $Z$ instead of the $m$ and $b$ of the fixed-pitch case. But the difference is much greater than that. The empirical chart-based constant-speed Bootstrap Approach lacks the analytic simplicity of its fixed-pitch cousin.

\section{CONCLUSION}

It is hoped that the relative simplicity of these procedures won't relegate them to the realm of idle curiosities and will encourage pilots to use the Bootstrap Approach to obtain good flight performance data specific to their own airplanes. $\square$

John T. Lowry holds a Ph.D. in Physics from the University of Texas at Austin. He is the owner of Flight Physics, an aviation physics consulting firm, in Billings, Mont.

\section{REFERENCES}

Diehl, W. S. (1936). Engineering aerodynamics. New York: Ronald Press.

Gagg, R. F., and Farrar, E. V. (1934). Altitude performance of aircraft engines equipped with gear-driven superchargers. SAE Transactions, 29, 217-223.

Lowry, J. T. (1995). Computing airplane performance with the bootstrap approach: $A$ field guide. Billings, MT: Flight Physics.

Lowry, J. T. (1996). Analytic v-speeds from linearized propeller polar. Journal of Aircraft, 33, 1.

Perkins, C. D., and Hage, R. E. (1949). Airplane performance stability and control New York: Wiley.

Smith, H. C. (1985). The illustrated guide to aerodynamics. Blue Ridge Summit, PA: Tab Books.

Von Mises, R. (1959). Theory of flight. New York: Dover. 